\title{
VALIDATION OF THE TOLNET LIDARS DURING SCOOP (SOUTHERn CaLIFornia Ozone ObSERVATION ProJeCT)
}

Thierry Leblanc $^{1 *}$, Maria-Jose Granados-Munoz ${ }^{1}$, Kevin Strawbridge ${ }^{2}$, Chris Senff ${ }^{3}$, Andy $^{4}$ Langford $^{3}$, Tim Berkoff ${ }^{4}$, Guillaume Gronoff ${ }^{4}$, Russel DeYoung ${ }^{4}$, Bill Carion ${ }^{4}$, G. Chen ${ }^{4}, J^{2}$ nn

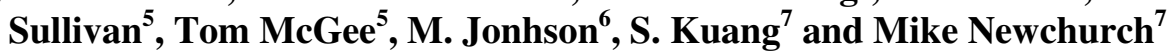

${ }^{I}$ California Institute of Technology, Jet propulsion Laboratory,USA, *thierry.leblanc@jpl,nasa.gov

${ }^{2}$ Environment and Climate Change Canada, Canada

${ }^{3}$ NOAA-Earth System Laboratory, USA

${ }^{4} N A S A$-Langley research Center, USA

${ }^{5}$ NASA-Goddard Space Flight Center, USA

${ }^{6}$ NASA-Ames Research Center, USA

${ }^{7}$ University of Alabama in Huntsville, USA

\begin{abstract}
Five TOLNet lidars participated to a validation campaign at the JPL-Table Mountain Facility, CA in August 2016. All lidars agreed within $\pm 10 \%$ of each other and within $\pm 7 \%$ of the ozonesondes. Centralized data processing was used to compare the uncertainty budgets. The results highlight the TOLNet potential to address science questions ranging from boundary layer processes to long range transport. TOLNet can now be seen as a robust network for use in field campaigns and long term monitoring.
\end{abstract}

\section{INTRODUCTION}

The Tropospheric Ozone Lidar Network (TOLNet) is a North-America-based network of six ozone differential absorption lidars dedicated to the study of tropospheric ozone variability at timescales ranging from a few minutes to several decades, and to satellite validation and model evaluation. The four mobile systems comprise AMOLITE from Environment Canada, LMOL from NASA Langley Research [1], TOPAZ from NOAA-Earth System Research Laboratory [2], and TROPOZ from NASA-Goddard Space flight Center [3]. The two systems built at fixed locations are operated by the University of Alabama in Huntsville, and the JPL-Table Mountain Facility [4].

In August 2016, leveraging from their nearby deployment for field campaigns, it was decided to deploy the TOPAZ and TROPOZ lidars at the Table Mountain Facility for an intercomparison campaign before returning to their home base. The other two TOLNet mobile lidars joined the campaign efforts, making a unique opportunity for five of the six TOLNet lidars to be inter-compared and validated. In support of the validation, the JPL lidar group launched 17 ozonesondes.

In this extended abstract, we show the preliminary results obtained from "Level 2" SCOOP data produced for the blind phase of the validation exercise. The focus is on the strictly-coincident lidar-ozonesonde profiles, starting at launch time and extending 30-minutes after launch. In addition to lidar-lidar and lidar-sonde comparisons, the lidars uncertainty budgets will be compared using a newly developed centralized data processing algorithm.

\section{DEPLOYMENT}

Three lidars (TOPAZ, TROPOZ and TMT) were co-located at the TMF main facility (elev. $2285 \mathrm{~m}$ above mean sea level-a.s.1.), while the two others (AMOLITE, LMOL) were located less than a quarter mile away (elev. $2270 \mathrm{~m}$ ), making all five systems nearly co-located. The campaign officially started on August 10, 2016 and ended on August 16, one day too early due to a local wildfire mandatory evacuation order. Each lidar acquired between 2 and 20 hours of data per day. The automated, autonomous system AMOLITE acquired data continuously during and after the campaign, making unprecedented 31 days uninterrupted tropospheric ozone measurements above the site. The TOPAZ instrument is equipped with a two-axis scanner, allowing pointing of the laser beam in any direction at various elevation angles besides the zenith. All lidars use more or less advanced aerosol measurement capability. 
For ozone measurements, all lidars use the same differential absorption technique, but at different wavelength pairs constrained by hardware configurations [1][2][3][4]. Three instruments use quadrupled Nd:YAG lasers to produce $266 \mathrm{~nm}$ beams. AMOLITE then uses a $\mathrm{CO}_{2}$ Raman cell to shift the wavelength to $287 \mathrm{~nm}$ and $299 \mathrm{~nm}$, while the JPL-TMF (later referred to as "TMT") and TROPOZ systems use a pair of $\mathrm{D}_{2}$ and $\mathrm{H}_{2}$ Raman cells to shift to $289 \mathrm{~nm}$ and $299 \mathrm{~nm}$. The other two lidars (TOPAZ and LMOL) use similar Ce:LiCAF lasers pumped by a quadrupled Nd:YLF laser to produce two wavelengths, tuned to approximately $287 \mathrm{~nm}$ and $294 \mathrm{~nm}$ during the SCOOP campaign.

The receiver configurations and detectors vary between the instruments, with telescope sizes ranging between $5 \mathrm{~cm}$ and $91 \mathrm{~cm}$ depending on instrument and intensity range considered. For ozone, all systems use photomultiplier tubes, and Licel transient recorders with analog detection and photon counters. Ozone profiles are retrieved either using both types of data acquisition systems (AMOLITE, LMOL, TOPAZ) or using photoncounting mode only (TROPOZ and TMT). In any case, the combination of multiple analog and photon counting pairs allows coverage of the entire lower and middle troposphere $(3-10 \mathrm{~km})$ by all five instruments and coverage of the upper troposphere $(10-16 \mathrm{~km})$ by three of them (AMOLITE, TROPOZ, and TMT).

During the campaign, the JPL lidar group launched ozonesondes at all possible times of the day, specifically, 2 sondes before sunrise, 4 sondes in the daytime morning hours, 4 sondes around midday, 3 sondes in the late afternoon hours, and 4 sondes after dark. Several surface ozone monitors, a ceilometer, water vapor Raman lidar, and stratospheric ozone and temperature lidar complemented the ozonesonde and tropospheric ozone lidar measurements.

\section{DATA PROCESSING}

For the blind phase of this validation exercise, all lidar groups were required to retrieve profiles with prescribed time and vertical resolutions. One data version included profiles retrieved at 10-minutes time resolution in order to produce curtain plots of ozone and allow altitude and time-dependent ozone variability investigations.

Another data version consisted of averaging the lidar raw data acquired during the first 30 minutes of each ozonesonde flight. For this dataset, a common vertical effective resolution scheme was used for all lidars. Averaging kernels were computed for each lidar separately, and for the ozone profiles, in order to obtain an effective resolution increasing linearly from $100 \mathrm{~m}$ near the surface to $1500 \mathrm{~m}$ at $8 \mathrm{~km}$ a.s.l., and then constant resolution of $1500 \mathrm{~m}$ at all altitudes above $8 \mathrm{~km}$. The effective resolution definition follows the NDACC (Network for the Detection of Atmospheric Composition Change) -standardized "Impulse Response"-based definition [5].

The differences between two coincident 30-min lidar profiles and between a 30-min lidar and ozonesonde profile were computed. Because of technical or operational constraints, all lidars were fully operational during only 7 of the 17 launches. In order to increase the comparison statistics, the lidar profiles were compared one-by-one to the ozonesondes, resulting in about 13 to 16 sondecoincident profiles for each lidar. The ozonesonde profiles were then used as the reference transfer to compare the lidars.

\section{RESULTS}

The campaign mean of the relative differences between the JPL-TMF tropospheric ozone lidar (TMT) and ozonesonde is shown in Figure 1. The number of coincidences (right plot) decreases with altitude, due to the decrease of the lidar signal-tonoise ratio and resulting lower profile cut-off from nighttime to daytime, as well as to the presence of optically thick clouds at 5-6 km on certain days. The grey-shaded area indicates the combined ozonesonde and lidar total standard uncertainties.
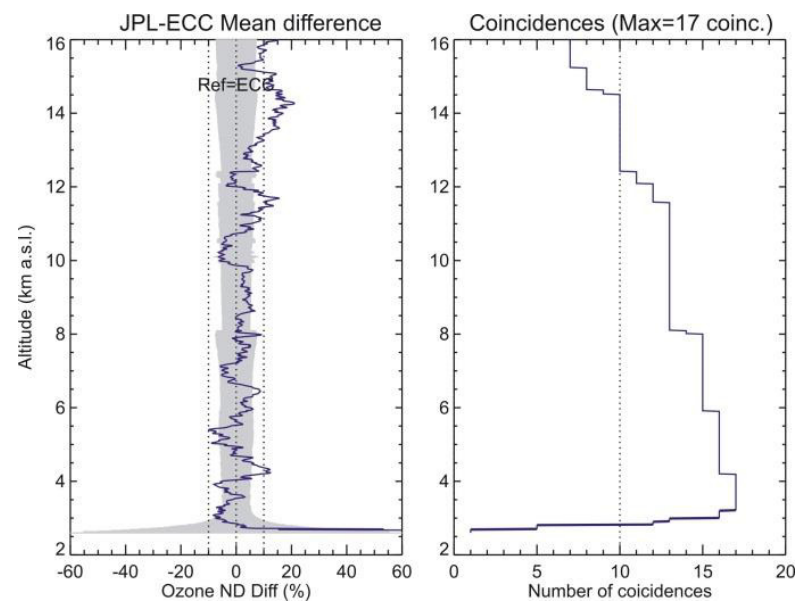

Figure 1 Left: Campaign-mean of the ozone relative differences (\%) between TMT lidar profiles and ozonesonde; Right: Number of coincidences as a function of altitude 
Overall, the TMT lidar and sonde profiles agree within $\pm 7 \%$, within the reported combined uncertainties. One exception is above $12 \mathrm{~km}$ where the difference can locally reach $15 \%$ (lidar higher than sonde). This bias is partially explained by possible loss of sonde-lidar co-location, but also by the fact that the TMT far-field (narrowfov) was occasionally impacted by slight misalignment. The TMT lidar-sonde difference also exceeds the combined uncertainty estimates at 4 and $5 \mathrm{~km}$, due to residual, uncorrected cloud contamination that occurred during the Aug. 13 and Aug. 16 mid-day measurements.

The mean differences shown in figure 1 for TMT were computed for all five lidars and composited together in Figure 2. The absolute differences (ppbv) are shown on the left, and the relative differences (\%) are shown on the right. The maximum number of coincidences with the ozonesondes varies between 13 and 17, depending on the lidar instrument considered. Below about $10 \mathrm{~km}$, all lidars agree with the ozonesondes within 4 ppbv or $7 \%$. Larger differences can be observed above $10 \mathrm{~km}$, partly explained by the increase in detection noise in the lidar data, as well as a possible loss of co-location between the sondes and the lidars.
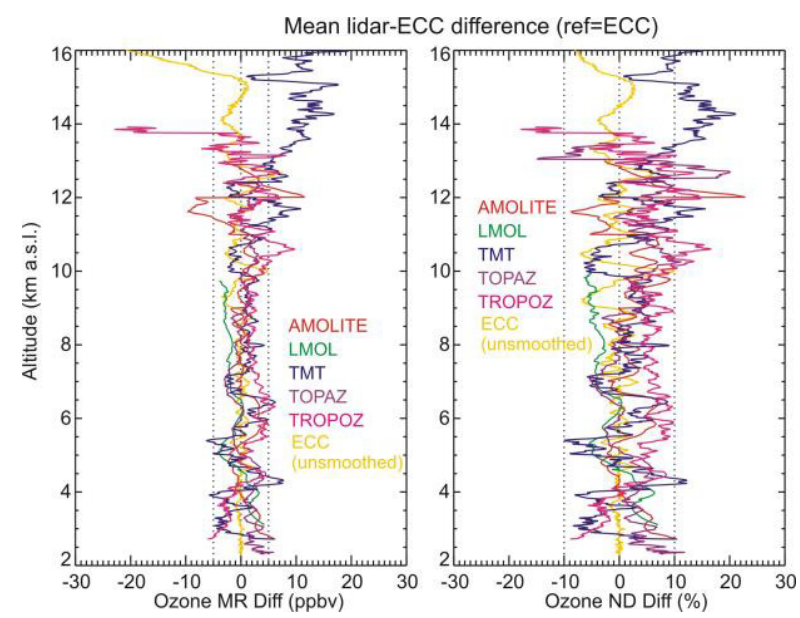

Figure 2 Campaign-mean of the differences (left: ppbv; right: \%) between all coincident 30-min average lidar and ozonesonde profiles

In order to further evaluate the capability of the TOLNet lidars, the consistency of their uncertainty budgets was investigated. A centralized data processing algorithm was recently developed at JPL, with the objective to produce profiles of quality similar to that of the individual in-house data processing algorithms, but with the added capability to produce profiles with standardized vertical resolutions and uncertainty budgets.

Figure 3 shows the ozone uncertainty budget computed by the centralized data processing algorithm for a 30-min nighttime ozone profile measured by TOPAZ on August 16, 2016. The colored curves show the individual uncertainty components, while the dash, black curves show the total uncertainty (ppbv on the left, $\%$ on the right).
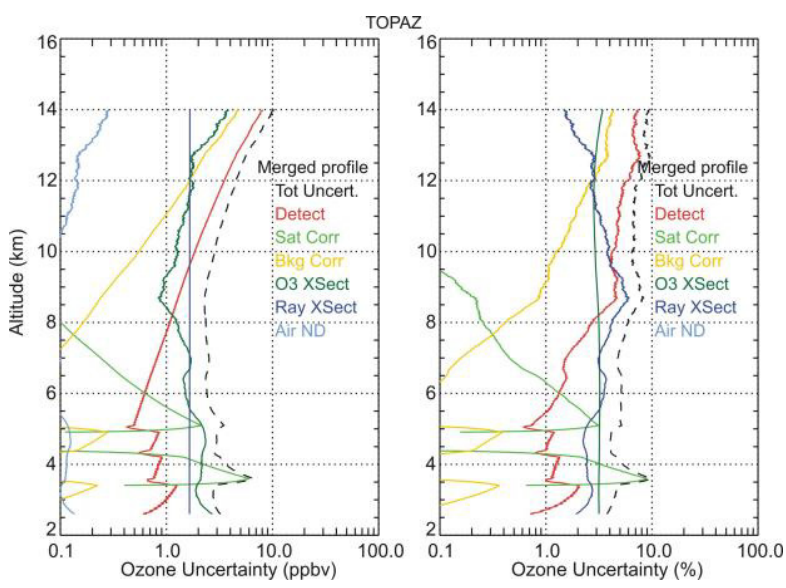

Figure 3 Example of standardized uncertainty budget, in this case for TOPAZ (30-min profile, nighttime)

Interestingly, in this example, at least four components play a significant role in the total budget. Below $3 \mathrm{~km}$, the ozone absorption crosssection uncertainty dominates (3\%). At $3.5 \mathrm{~km}$ the saturation correction uncertainty peaks at $9 \%$. Above $4 \mathrm{~km}$, uncertainty owed to the ozone absorption cross-section and Rayleigh extinction cross-sections uncertainties is of the same order of magnitude (3\%). Finally, above $10 \mathrm{~km}$, the detection noise uncertainty dominates (4\% increasing to $8 \%$ ). This example of uncertainty budget is quite different from that computed for TMT, where saturation correction uncertainty and detection noise play a more significant role throughout the profile (not shown).

The ozone total uncertainty computed by the centralized data processing algorithm for all five lidars and for the same 30-min averaged profile is plotted in Figure 4. The figure shows that total uncertainty can vary significantly from one lidar instrument to another. Larger uncertainty for TMT below $5.5 \mathrm{~km}$ is due to a combination of low STNR and inadequate common SCOOP vertical resolution scheme used in the near-field channels. Larger uncertainty at $8 \mathrm{~km}$ is associated with a large saturation correction uncertainty for the farfield channels. The TMT instrument was designed 
and optimized for nighttime, upper tropospheric and lower stratospheric measurements, which explains its atypical uncertainty budget compared to the other four systems optimized for air quality studies.

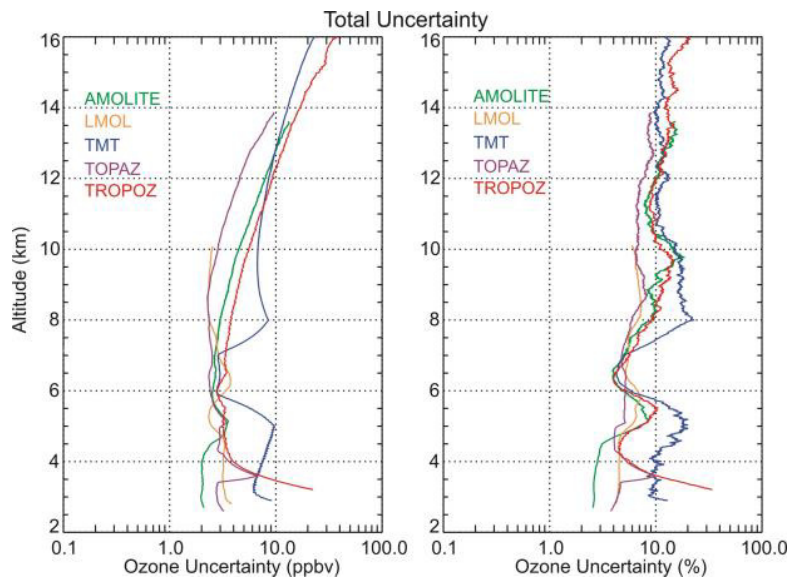

Figure 4 Total uncertainty computed by the centralized data processing algorithm for all 5 lidars (30-min profile, nighttime)

\section{CONCLUSIONS}

In August 2016, five (out of six) TOLNet lidars were deployed at the JPL-Table Mountain Facility, CA for a 7-day-long intercomparison campaign. More than 50 hours of lidar measurements were acquired for each of the lidar systems, and 18 ozonesondes were launched from the site (1 to 6 launches per day).

All lidars were found to agree within $\pm 10 \%$ of each other and within $\pm 7 \%$ of the ozonesonde throughout the altitude range 3-10 km a.s.l., which is typically within the reported uncertainties.

A centralized data processing algorithm was used to further compare the lidars, specifically allowing a quantitative intercomparison of the uncertainty budgets using standardized definitions. Interinstrument differences in the magnitude of individual components such as detection noise uncertainty or saturation correction uncertainty revealed that dominant uncertainty components can vary significantly from one lidar to another, thus highlighting the diversity of the TOLNet "fleet" and its potential for science applications ranging from small-scale boundary layer processes to long range transport in the upper troposphere.

Yet the present results from the SCOOP Level 2 data remain preliminary. A fully-validated version (known as "SCOOP Level 3" data) will be released during the spring of 2017 and publicly available for download from the TOLNet website https://www-air.larc.nasa.gov/missions/TOLNet.

The lidar-lidar and lidar-sonde differences, as well as ozone total uncertainty are expected to decrease with this new release.

The SCOOP campaign results showed that the TOLNet lidars are now mature enough to constitute a robust reference network for use in field campaigns as well as long term monitoring.

\section{ACKNOWLEDGEMENTS}

This work is supported by the TOLNet program developed by NASA's Science Mission Directorate. Part of this work was carried out at the Jet Propulsion Laboratory, California Institute of Technology, under agreements with the National Aeronautics and Space Administration. The authors would like to thank the entire JPLTMF Staff and Lidar Group for their sustained hard work throughout the campaign.

\section{References:}

[1] De Young, R., et al., 2017: Langley mobile ozone lidar: ozone and aerosol atmospheric profiling for air quality research, Appl. Opt. 56(3), 721-730, 2017.

[2] Alvarez, R. J., et al., 2012: Reconfiguration of the NOAA TOPAZ Lidar for Ground-based Measurement of Ozone and Aerosol Backscatter, Proceedings of the 26th ILRC, Porto Heli, Greece, 25-29 June 2012, pp. 249 $252,2012$.

[3] Sullivan, J. T., et al., 2014: A mobile differential absorption lidar to measure subhourly fluctuation of tropospheric ozone profiles in the Baltimore-Washington, D.C. region, Atmos. Meas. Tech., 7, 3529-3548, 2014.

[4] McDermid, I. S., et al., 2002: Redesign and improved performance of the tropospheric ozone lidar at the Jet Propulsion Laboratory Table Mountain Facility, Appl. Opt., 41, 75507555, 2002.

[5] Leblanc, T., et al., 2016: Proposed standardized definitions for vertical resolution and uncertainty in the NDACC lidar ozone and temperature algorithms - Part 1: Vertical resolution, Atmos. Meas. Tech., 9, 4029-4049, 2016. 